\title{
Increased activation of p38 MAPK in COPD
}

\author{
T. Renda*,", S. Baraldo", G. Pelaia*, E. Bazzan`, G. Turato", A. Papi ${ }^{+}$, P. Maestrelli $^{\S}$, \\ R. Maselli*, A. Vatrella\#, L.M. Fabbri ${ }^{\dagger}$, R. Zuin ${ }^{\star}$, S.A. Marsico ${ }^{\#}$ and M. Saetta
}

ABSTRACT: Inflammation, oxidative stress and apoptosis, which are involved in chronic obstructive pulmonary disease (COPD) pathogenesis, may activate the p38 subgroup of mitogenactivated protein kinases (MAPKs). Therefore, the aim of the present study was to evaluate the expression of the phosphorylated, active form of p38 MAPK (phospho-p38) in the lungs of COPD patients.

Surgical specimens were obtained from 18 smokers with COPD at different stages of disease severity, plus nine smoking and eight nonsmoking subjects with normal lung function. Phosphop38+ cells were quantified by immunohistochemistry in both alveolar spaces and alveolar walls. Moreover, a Western blot analysis of phospho-p38 and total p38 $\alpha$ isoform expressed by alveolar macrophages was performed.

Phospho-p38+ alveolar macrophages and phospho-p38+ cells in alveolar walls were increased in patients with severe and mild/moderate COPD, compared with smoking and nonsmoking controls. Moreover, they were inversely correlated to values of forced expiratory volume in one second (FEV 1 ) and $F E V_{1} /$ forced vital capacity. Western blot analysis showed that phosphorylated p38, but not the total p38 $\alpha$ isoform, was specifically increased in alveolar macrophages from COPD patients.

Activation of the p38 mitogen-activated protein kinase pathway appears to be involved in the pathogenesis of chronic obstructive pulmonary disease. The present findings suggest that this protein may be a suitable pharmacological target for therapeutic intervention.

KEYWORDS: Airflow limitation, chronic obstructive pulmonary disease, cigarette smoking, phospho-p38 mitogen-activated protein kinases

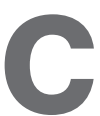
igarette smoke plays a crucial role in the pathogenesis of chronic obstructive pulmonary disease (COPD). Much of the information concerning COPD pathogenesis comes from studies performed in animal models or experimental in vitro systems, which do not always directly reflect what is occurring in human disease. However, it is well known that oxidants and oxidative stress due to cigarette smoking promote lung inflammation, which is mediated, at least in part, by activation of the transcription factors nuclear factor (NF)- $\kappa \mathrm{B}$ and activator protein (AP)-1, coordinating the expression of several genes thought to be important in COPD, such as interleukin (IL)- 8 and tumour necrosis factor (TNF)- $\alpha$ [1-3]. These pro-inflammatory cytokines and chemokines, together with IL-1 $\beta$, strongly activate the p38 subgroup of mitogen-activated protein kinases (MAPKs), a family of signal transduction enzymes that also include extracellular signal-regulated kinases (ERK) and c-jun $\mathrm{NH}_{2}$-terminal kinases (JNK) [4] MAPKs are organised hierarchically into three modules, operating via a phosphorylation cascade that converts them into activated forms, thereby enabling their interaction with cytoplasmic substrates and translocation to the nucleus, where many MAPK targets, such as transcription factors and histones, are located [5]. The ERK pathway is stimulated in particular by G-protein coupled receptors and growth factors involved in cell proliferation, differentiation and survival, whereas JNK and p38 modules are activated mainly by cytokines implicated in inflammation and apoptosis [6]. Within the MAPK family, both the JNK and the p38 subgroups are involved in mediating proinflammatory responses, though p38 seems to play a prominent role in COPD. Indeed, p38 activation in key inflammatory cell types correlates with disease initiation and progression [7]. p38 also appears to be the most effective MAPK in stabilising, at post-transcriptional level, the mRNAs for cytokines and chemokines relevant to COPD pathogenesis, such as TNF- $\alpha$, IL-1 $\beta$, IL-6 and IL-8 [8]. Conversely, p38 inhibitors are able to attenuate disease severity in animal models of COPD; therefore, p38 currently represents the main focus of novel anti-inflammatory therapies based on MAPK inhibition [9]. Four different isoforms of p38

\section{AFFILIATIONS}

*Dept of Experimental and Clinical Medicine, University "Magna Græcia" of Catanzaro, Catanzaro,

"Dept of Cardiothoracic and Respiratory Sciences, Second University of Naples, Naples, Depts of "Cardiac, Thoracic and Vascular Sciences, and

${ }^{\S}$ Environmental Medicine and Public Health, University of Padova, Padova, +Dept of Clinical and Experimental Medicine, University of Ferrara, Ferrara, and

${ }^{f}$ Dept of Oncology, Haematology and Respiratory Disease, University of Modena and Reggio Emilia, Modena, Italy.

CORRESPONDENCE

M. Saetta

Dept of Cardiac, Thoracic and

Vascular Sciences

Section of Respiratory Diseases

University of Padova

via Giustiniani 3

Padova

Italy

Fax: 390498213110

E-mail: marina.saetta@unipd.it

Received:

March 272007

Accepted after revision:

October 162007

SUPPORT STATEMENT

The present study was supported by the University of Padova, MOSTRE,

Padova, Italy.

STATEMENT OF INTEREST

A statement of interest for this study can be found at

www.erj.ersjournals.co.uk/misc/ statements.shtml

European Respiratory Journal Print ISSN 0903-1936 Online ISSN 1399-3003 
MAPK are known, which are designated $\alpha, \beta, \gamma$, and $\delta$, respectively, and appear to be characterised by different functional patterns and cell expression profiles. In particular, lung macrophages predominantly express the $\alpha$ isoform; these cells also express p38 $\delta$, but not $\mathrm{p} 38 \beta$ or $\mathrm{p} 38 \gamma$ [10].

The initial inflammatory events leading to COPD pathogenesis probably represent a reaction of the airways to nonspecific damaging agents. However, COPD is associated with an abnormal lung inflammation that persists even in patients who have stopped smoking [11]. It can be hypothesised that some inappropriate and self-amplifying pathogenic circuits may prevent the resolution of the inflammatory response in susceptible individuals. Within this biological context, activation of a key proinflammatory signalling pathway, such as p38 MAPK, could play a crucial role. The current authors therefore investigated the expression of the phosphorylated, active form of p38 in peripheral lung tissue as well as in primary cultures of alveolar macrophages obtained from smokers with COPD, in comparison with both smoking and nonsmoking controls. Preliminary results of the present study have been reported previously in abstract form [12].

\section{METHODS}

\section{Subject characteristics}

Four groups of subjects undergoing lung resection for solitary peripheral carcinoma or lung volume reduction surgery (LVRS) were recruited to the study: seven smokers with severe/very severe COPD (Global Initiative on Chronic Obstructive Lung Disease (GOLD) stages 3 and 4), 11 smokers with mild/moderate COPD (GOLD stages 1 and 2), nine smoking and eight nonsmoking controls (asymptomatic and with normal lung function). Five out of the severe/very severe COPD subjects underwent LVRS, while two underwent resection for lung cancer. All the patients with mild/moderate disease, the control smokers and the nonsmokers underwent resection for lung cancer. Pulmonary function tests were performed during the week before surgery. Fixed airway obstruction was defined according to the recent guidelines [13] as a ratio of forced expiratory volume in one second (FEV1) to forced vital capacity (FVC) of $<70 \%$ predicted; all patients had a reversibility of $<12 \%$ after inhalation of $400 \mu \mathrm{g}$ salbutamol.

Chest radiographs were obtained within $48 \mathrm{~h}$ of lung function studies. In a subset of patients, scores for emphysema were calculated on the basis of criteria for evaluation of roentgenographic signs of emphysema as previously described [14]. Briefly, these included signs of overinflation, i.e. depression and flattening of hemidiaphragms (evaluated on both the posteroanterior and the lateral views) and increased retrosternal space, which were scored individually from 0 to 3 . For the evaluation of pulmonary vascular abnormalities, the posteroanterior film was divided into four quadrants at the level of the carina. Each quadrant was analysed for the presence of different vascular abnormalities, which were assigned an individual score from 0 to 0.5 . The partial scores from the four quadrants were summed and combined with the overinflation score to yield a cumulative score that ranged $0-16$.

During the month preceding the study, patients with COPD had no exacerbations, which are defined as increased dyspnoea associated with a change in the quality and quantity of sputum, leading the subject to seek medical attention [15]. All subjects had been free of acute upper respiratory tract infections and none had received bronchodilators within the previous $48 \mathrm{~h}$. Subjects were nonatopic (negative skin tests for common allergen extracts) and had no past history of asthma or allergic rhinitis.

The present study conformed to the Declaration of Helsinki [16], and informed written consent was obtained for each subject undergoing surgery or bronchoscopy.

\section{Immunohistochemistry}

Tissue blocks were taken from the subpleural parenchyma of the lobe obtained at surgery, avoiding areas with tumours. Samples were fixed in $4 \%$ formaldehyde and embedded in paraffin, as described previously [17]. Immunohistochemistry was performed using a rabbit monoclonal primary antibody against the active form of p38 (phospho-p38) MAPK (dilution 1:100; Cell Signaling Technology Inc., Danvers, MA, USA), the avidin-biotin complex (ABC-complex kit; Dako Ltd, High Wycombe, UK) and detection by Fast Red substrate staining (Dako Ltd).

Phospho-p38 immunostaining was quantified in both alveolar walls and alveolar macrophages as follows. For cell counts in the lung parenchyma, only the alveolar walls with a single layer of cells were examined, to avoid bias caused by technical artefacts such as adjacent alveolar walls [18]. The number of positively stained cells within the alveolar walls was computed using a light microscope (BX41; Olympus, Tokyo, Japan), connected to a video recorder linked to a computerised image system (Image-Pro Plus; Media Cybernetics Inc., Bethesda, MD, USA). Briefly, at a magnification of $\times 630$, the length of the alveolar walls was measured, and the number of phosphop38-positive MAPK cells within these alveolar walls was counted. A total of 10 fields, distributed randomly across the slide, were evaluated for each subject and the result was expressed as the number of positive cells $\cdot \mathrm{mm}^{-1}$ of alveolar wall as previously described [17]. Briefly, for evaluation of phospho-p38 expression in the alveolar macrophages, $\geqslant 100$ macrophages inside the alveolar spaces were evaluated. Alveolar macrophages were defined as mononuclear cells with a well-represented cytoplasm, present in the alveolar spaces and not attached to the alveolar walls. Results were expressed as number of positive macrophages-high-power field $(\mathrm{hpf})^{-1}$. To correct for possible differences in absolute number of macrophages, results were also expressed as phospho-p38-positive macrophages as a percentage of total macrophages [18].

Immunohistochemical analysis of inflammatory cells infiltrating the alveolar walls was performed. Briefly, mouse monoclonal antibodies were used for identification of neutrophils (anti-elastase M752; Dako Ltd), macrophages (anti-CD68 M814; Dako Ltd) and CD8+ cells (anti-CD8 M7103; Dako) as previously described [19]. A total of 10 fields, distributed randomly across the slide, were evaluated for each subject and the result was expressed as the number of positive cells $\cdot \mathrm{mm}^{-1}$ of alveolar wall as previously described [17].

Cases were coded and measurements made without knowledge of clinical and functional data. 


\section{Cell cultures and Western blotting}

Cells from two patients with COPD, one smoking and one nonsmoking control (both with normal lung function) were obtained at bronchoscopy, collected in sterile saline solution and centrifuged at $500 \times g$ for $5 \mathrm{~min}$ [20]. The supernatant was removed, cellular pellets were washed and resuspended in $10 \mathrm{~mL}$ of Roswell Park Memorial Institute (RPMI) medium with added antibiotics $\left(100 \mathrm{U} \cdot \mathrm{mL}^{-1}\right.$ penicillin and $100 \mu \mathrm{g} \cdot \mathrm{mL}^{-1}$ streptomycin; Sigma, St Louis, MO, USA) and Fungizone (1 $\mu \mathrm{g} \cdot \mathrm{mL}^{-1}$; GIBCO BRL, Gaithersburg, MD, USA). Cell types were determined by morphology using Diff-Quick staining (Baxter, Miami, FL, USA); $>95 \%$ of cells in each cell preparation were macrophages. Cells were diluted to $1 \times 10^{6}$ macrophages $\cdot \mathrm{mL}^{-1}$, plated onto six-well plates $\left(1 \mathrm{~mL} \cdot \mathrm{well}^{-1}\right)$ and allowed to incubate for $2-4 \mathrm{~h}$ to facilitate attachment. Subsequently, the medium was removed and fresh medium was added. The cells were incubated overnight at $37^{\circ} \mathrm{C}$ with $5 \% \mathrm{CO}_{2}$.

After culture, cells were trypsinised for $5 \mathrm{~min}$, resuspended in supplemented RPMI, centrifuged at $4^{\circ} \mathrm{C}$ for $5 \mathrm{~min}$, and then lysed for Western blotting in radioimmunoprecipitation assay (RIPA) buffer (150 mM NaCl, $1.5 \mathrm{mM} \mathrm{MgCl}, 10 \mathrm{mM} \mathrm{NaF}, 10 \%$ glycerol, 4 mM EDTA, 1\% Triton X-100, 0.1\% sodium dodecyl sulphate (SDS), 1\% deoxycholate, 50 mM HEPES, pH 7.4, plus phosphatase- and protease-inhibitor mixture, $25 \mathrm{mM} \beta$-glycerophosphate, $1 \mathrm{mM} \mathrm{Na} \mathrm{VO}_{4}, 1 \mathrm{mM}$ phenylmethanesulphonylfluoride, $10 \mu \mathrm{g} \cdot \mathrm{mL}^{-1}$ leupeptin, $10 \mu \mathrm{g} \cdot \mathrm{mL}^{-1}$ aprotinin). Protein extracts were then separated using $12.5 \%$ SDS-polyacrylamide gel electrophoresis (SDS-PAGE) and transferred on to polyvinylidene difluoride membranes (Amersham Pharmacia, Little Chalfont, UK). Immunoblotting was performed using the same anti-phospho-p38 monoclonal antibody used for immunohistochemistry. After being "stripped", membranes were re-probed with an anti-p38 $\alpha$ antibody (Autogen Bioclear; Calne, Wiltshire, UK). Antibody binding was visualised using enhanced chemiluminescence (ECL-Plus; Amersham Pharmacia).

\section{Statistical analysis}

Group data are expressed as mean \pm SEM or as median (range). Differences between groups were analysed using the following tests for multiple comparisons: ANOVA for clinical data; and the Kruskall-Wallis test for histological data. The MannWhitney U-test was carried out after the Kruskall-Wallis test when appropriate. Spearman's rank correlation coefficient test was used to examine the association between histological parameters and functional data. Probability values of $\mathrm{p}<0.05$ were accepted as significant.

\section{RESULTS}

\section{Clinical findings}

Table 1 shows the clinical characteristics of the subjects examined. The four groups of subjects were similar with regard to age and the three groups of smokers had similar values of smoking pack-yrs. The three groups of smokers included both current smokers and ex-smokers, and all exsmokers had quit smoking for $>1$ yr. As expected from the selection criteria, the values of FEV1 \% pred and FEV1/FVC ratio were different in the four groups $(\mathrm{p}<0.0001)$ : smokers with severe COPD had a significantly lower FEV1 \% pred and FEV1/FVC ratio than smokers with mild/moderate COPD, smokers with normal function and nonsmokers $(\mathrm{p}<0.0001$ for all comparisons). Moreover, smokers with mild/moderate COPD had a significantly lower \% pred FEV1 and FEV1/FVC ratio than smokers with normal lung function $(p<0.0005)$ and nonsmokers $(p<0.002)$. In smokers with COPD, the average response to bronchodilator was $5 \%$. The four groups of subjects also differed in arterial oxygen tension $\left(\mathrm{Pa}, \mathrm{O}_{2}\right)$ values $(\mathrm{p}=0.008)$. Indeed, smokers with severe COPD had lower $\mathrm{Pa}, \mathrm{O}_{2}$ values than smokers with mild/moderate $\operatorname{COPD}(p=0.03)$, smoking $(p=0.005)$ and nonsmoking controls $(p=0.04)$, while no significant differences were observed among the other three groups of subjects examined. Moreover, there were no

\section{TABLE 1 Clinical characteristics of subjects}

\begin{tabular}{|c|c|c|c|c|}
\hline & Severe/very severe & Mild/moderate & Smokers & Nonsmokers \\
\hline Subjects M/F n & $5 / 2$ & $10 / 1$ & $9 / 0$ & $3 / 5$ \\
\hline Age yrs & $65 \pm 4$ & $65 \pm 3$ & $65 \pm 3$ & $63 \pm 4$ \\
\hline Smoking history pack-yrs & $47 \pm 11$ & $43 \pm 5$ & $47 \pm 9$ & \\
\hline FEV1/FVC \% & $39 \pm 5^{+}$ & $65 \pm 1^{f}$ & $80 \pm 2$ & $79 \pm 2$ \\
\hline Emphysema score & $10 \pm 1$ & $4 \pm 1$ & & \\
\hline$D \mathrm{~L}, \mathrm{Co}^{\#} \%$ & $32 \pm 8$ & $90 \pm 15$ & & \\
\hline $\mathbf{R V}^{*} \%$ pred & $181 \pm 25$ & $94 \pm 18$ & & \\
\hline $\mathrm{Pa}, \mathrm{O}_{2} \mathrm{mmHg}$ & $68 \pm 6^{*}$ & $81 \pm 2$ & $89 \pm 3$ & $89 \pm 7$ \\
\hline $\mathrm{Pa}, \mathrm{CO}_{2} \mathrm{mmHg}$ & $39 \pm 2$ & $41 \pm 1$ & $41 \pm 4$ & $38 \pm 1$ \\
\hline
\end{tabular}

Data are expressed as mean \pm SEM, unless otherwise stated. COPD: chronic obstructive pulmonary disease; M: male; F: female; FEV1: forced expiratory volume in one second; \% pred: \% predicted; FVC: forced vital capacity; $D L, C O$ : diffusing capacity of the lung for carbon monoxide; RV: residual volume; $P a, O_{2}$ : arterial oxygen tension; $\mathrm{Pa}_{1} \mathrm{CO}_{2}$ : arterial carbon dioxide tension. ${ }^{\#}$ : D L, CO was available in seven subjects; $"$ : measurements of RV and emphysema score were available in 10 subjects. ${ }^{+}$ $\mathrm{p}<0.0001$ versus mild/moderate COPD, control smokers and nonsmokers; ${ }^{\text {: }} \mathrm{p}<0.002$ versus control smokers and nonsmokers; ${ }^{*}: \mathrm{p}<0.05$ versus mild/moderate COPD, control smokers and nonsmokers. 
significant differences in arterial carbon dioxide tension $\left(\mathrm{Pa}_{\mathrm{a}} \mathrm{CO}_{2}\right)$ among the four subject groups. Average values of residual volume (RV; \% pred) and radiological emphysema score were higher in smokers with severe COPD than in smokers with mild/moderate COPD, whereas the opposite was true with regard to the average $\%$ values of diffusing capacity of the lung for carbon monoxide $(D \mathrm{~L}, \mathrm{CO})$. However, since measurements of RV (together with emphysema score) and $\mathrm{DL}, \mathrm{CO}$ were performed in only a subset of patients, a formal statistical analysis was not applied to these parameters.

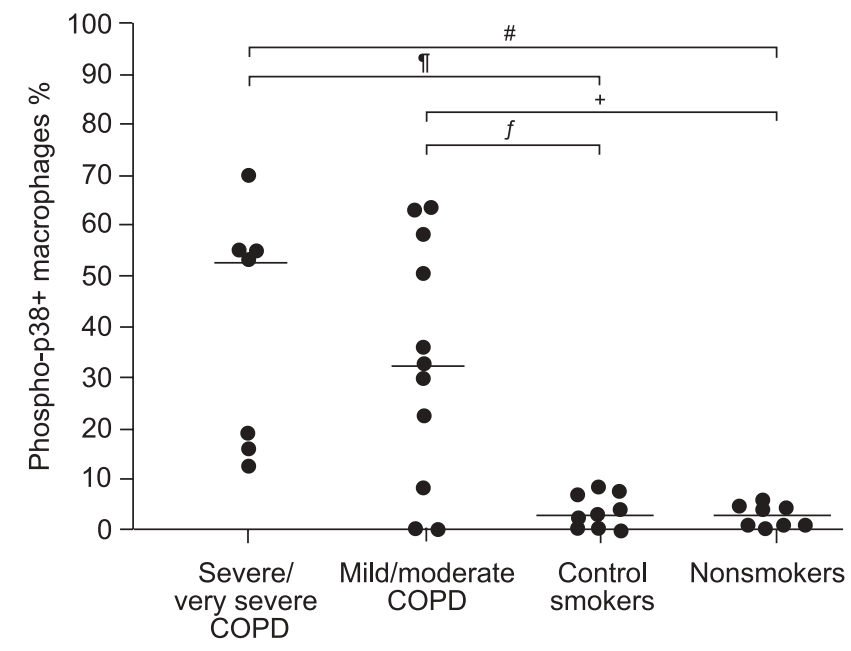

FIGURE 1. Individual counts for activated p38 mitogen-activated protein kinase-positive (phospho-p38+) macrophages in the alveolar spaces of smokers with severe/very severe chronic obstructive pulmonary disease (COPD), smokers with mild/moderate COPD, control smokers and nonsmoking subjects with normal lung function. Data are expressed as \% of alveolar macrophages. —: median values. ${ }^{\#}: p=0.001 ;{ }^{\top}: p=0.0008 ;{ }^{+}: p=0.02 ;{ }^{f}: p=0.01$.

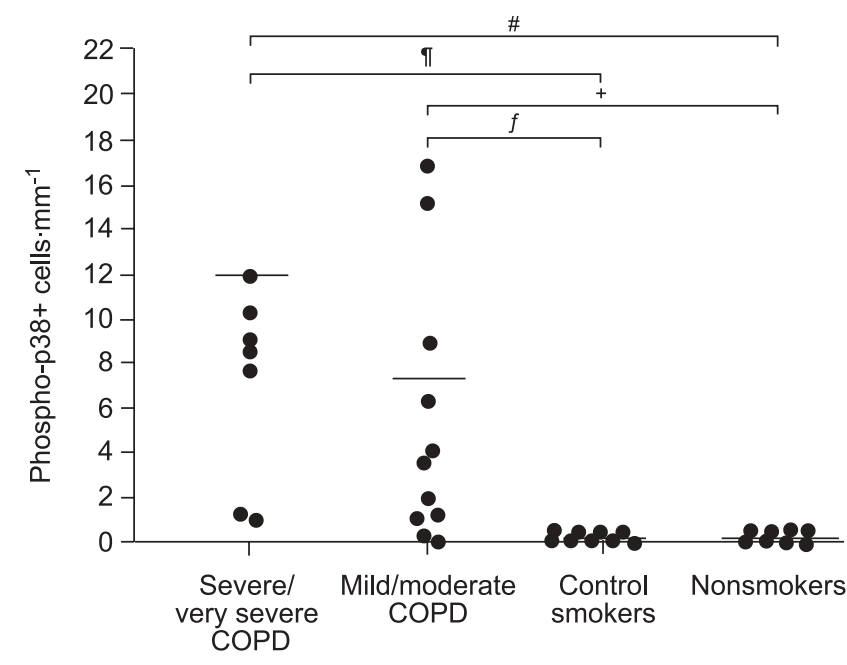

FIGURE 2. Individual counts for activated p38 mitogen-activated protein kinase-positive (phospho-p38+) cells within alveolar walls of smokers with severe/ very severe chronic obstructive pulmonary disease (COPD), smokers with mild/ moderate COPD, control smokers and nonsmoking subjects with normal lung function. Data are expressed as number of cells $\cdot \mathrm{mm}^{-1}$ of alveolar wall. — : median values. ${ }^{*}: p=0.0004 ;{ }^{\natural}: p=0.0005 ;^{+}: p=0.0005 ;{ }^{f}: p=0.006$.

\section{Immunohistochemical findings}

The results of phospho-p38 quantification in alveolar macrophages and alveolar walls are shown in figures 1-3. The median numbers and relative ranges of cells expressing phospho-p38 are shown in table 2.

Phospho-p38+ macrophages as a \% of total macrophages were increased in patients with severe COPD compared with smokers with normal lung function $(\mathrm{p}=0.0008)$ and nonsmokers $(p=0.001)$. Phospho-p38+ macrophages were also increased in smokers with mild/moderate COPD compared with both smoking $(p=0.01)$ and nonsmoking controls $(p=0.02)$. No significant difference was detected between smokers with severe COPD and those with mild/moderate COPD, nor between smokers with normal lung function and nonsmokers. Similar findings were obtained when the results were expressed as number of phospho-p38+ macrophages $\cdot \mathrm{hpf}^{-1}$ (table 2).
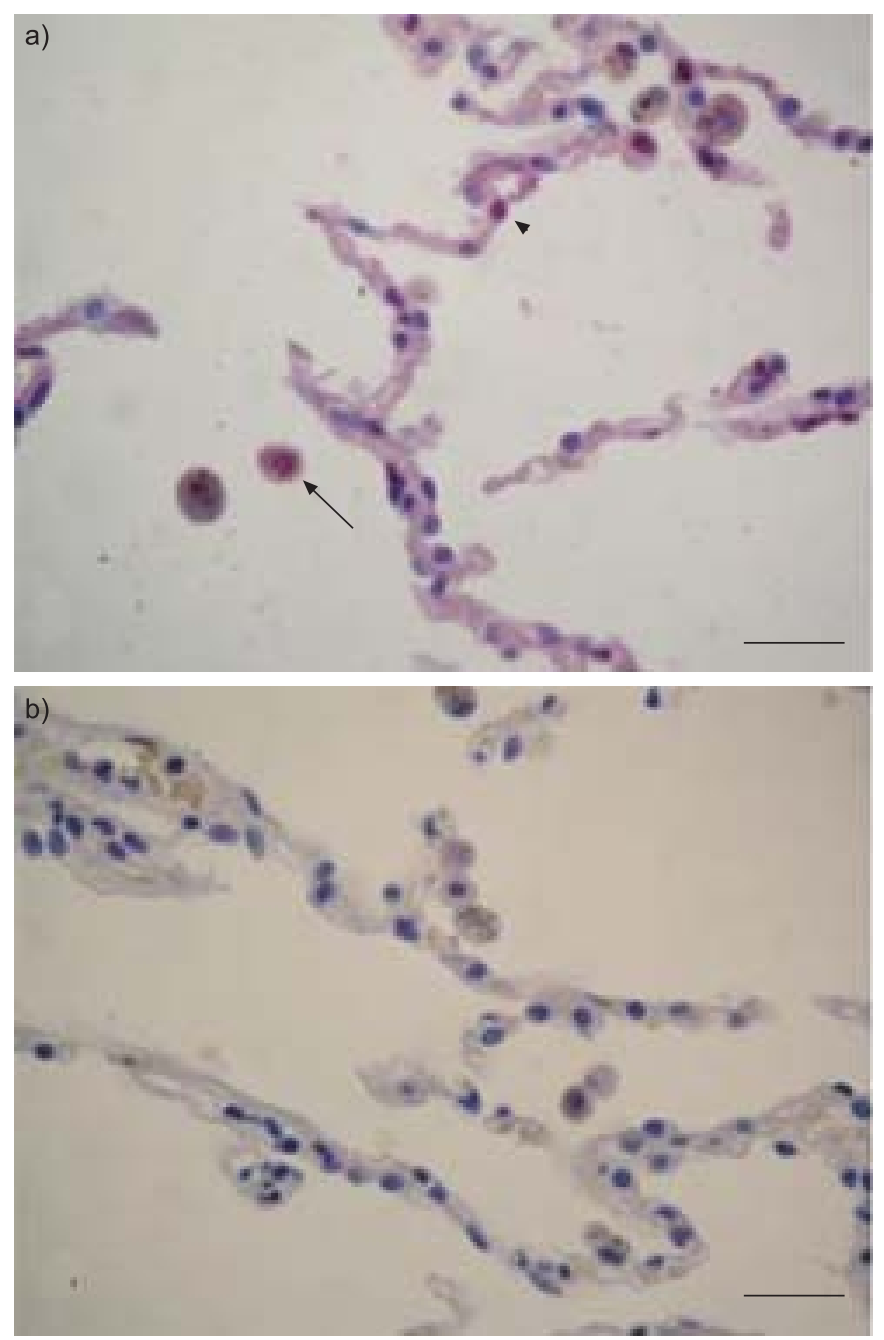

FIGURE 3. Immunostaining in a) a smoker with COPD and b) a smoker with normal lung function showing activated p38 mitogen-activated protein kinasepositive (phospho-p38+) cells within alveolar wall and phospho-p38+ alveolar macrophages with anti-phospho-p38 monoclonal antibody. Arrow: a phosphop38+ alveolar macrophage; arrowhead: a phospho-p38+ cell within the alveolar wall. Scale bars $=150 \mu \mathrm{m}$. 


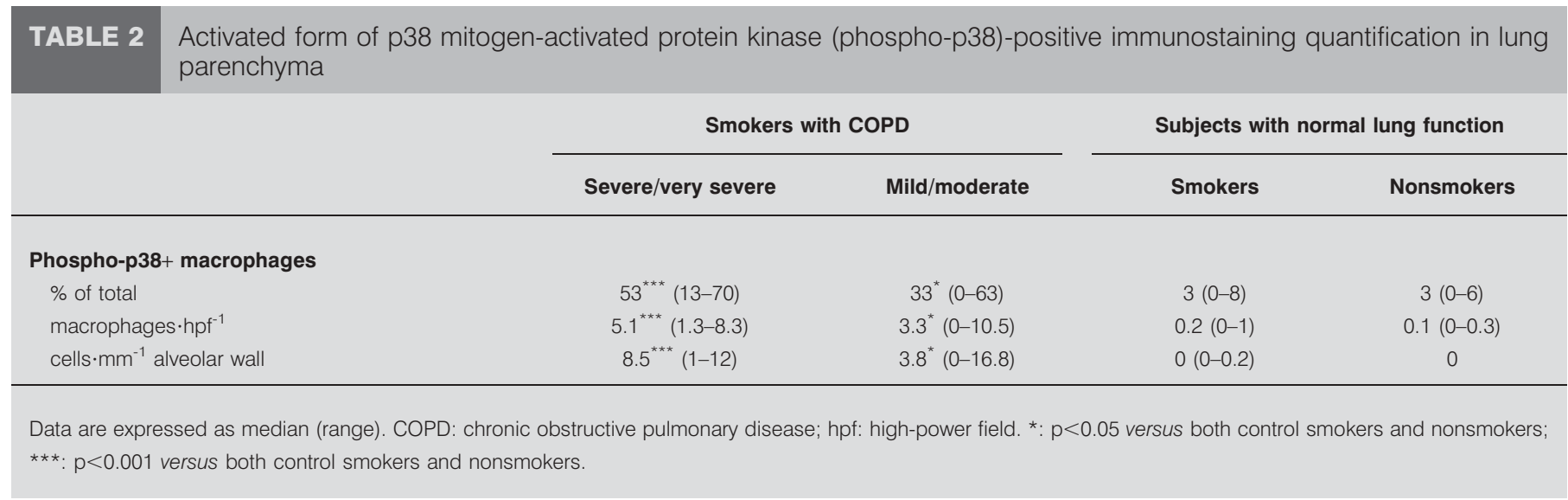

Significant differences among the four groups of subjects examined were observed also in phospho-p38+ cells in alveolar walls $(p<0.0001)$. Indeed, the number of phospho-p38+ cells $\cdot \mathrm{mm}^{-1}$ was increased in the group of severe COPD patients compared with smoking $(\mathrm{p}=0.0005)$ and nonsmoking controls $(\mathrm{p}=0.0004)$. Phospho-p38+ cells within alveolar walls were also increased in smokers with mild/moderate COPD compared with both smoking $(p=0.006)$ and nonsmoking controls $(\mathrm{p}=0.0005)$. Once more, no significant difference was observed between smokers with severe COPD and those with mild/ moderate COPD, nor between smokers with normal lung function and nonsmokers (table 2).

Examination of the different inflammatory cell subtypes found that the number of CD8+ T-cells infiltrating the alveolar walls, but not of macrophages and neutrophils, was significantly different among the four groups of subjects examined $(p=0.002)$. In particular, CD8+ T-cells were increased in both smokers with severe COPD (median (range): 8.3 (6.9-14.4) cells $\left.\cdot \mathrm{mm}^{-1}\right)$ and smokers with mild/moderate COPD (5.2 (1.813) cells $\left.\cdot \mathrm{mm}^{-1}\right)$ compared with control smokers (2.4 (1.4-2.6) cells $\cdot \mathrm{mm}^{-1} ; \mathrm{p}=0.004$ and $\mathrm{p}=0.03$, respectively) and nonsmokers $\left(2(0-3)\right.$ cells $\cdot \mathrm{mm}^{-1} ; \mathrm{p}=0.008$ and $\mathrm{p}=0.03$, respectively). No significant difference was observed between smokers with severe COPD and those with mild/moderate COPD, nor between smokers with normal lung function and nonsmokers.

The total length of alveolar walls examined was (mean \pm SEM) $4.3 \pm 0.4 \mathrm{~mm}$ in smokers with severe COPD, $5.3 \pm 0.4 \mathrm{~mm}$ in smokers with mild/moderate COPD, $6.6 \pm 0.4 \mathrm{~mm}$ in smokers with normal lung function and $6.8 \pm 0.2 \mathrm{~mm}$ in nonsmokers.

When all the smoking subjects were considered as one group, inverse correlations were observed between phospho-p38+ macrophages and FEV1 \% pred values $(p=0.008, r=-0.52)$ or FEV1/FVC ratio $(p=0.006, r=-0.54)$. Inverse correlations were also found between phospho-p38+ cells within alveolar walls and the values of FEV1 \% pred $(p=0.001, r=-0.65)$ and FEV1/ FVC ratio $(p=0.0003, r=-0.71)$. Furthermore, there was a negative correlation between the number of phospho-p38+ cells within alveolar walls and $\mathrm{Pa}_{1} \mathrm{O}_{2}$ values $(\mathrm{p}=0.04, \mathrm{r}=-0.41$ ).

When the relationship with inflammatory cells was considered, phospho-p38+ cells in alveolar walls showed a significant positive correlation with the numbers of CD8+ cells infiltrating the alveolar walls $(p=0.0006 ; \mathrm{r}=0.75)$, but with neither neutrophils nor macrophages.

Finally, phospho-p38 expression was not correlated with cumulative smoking history and was not influenced by current smoking status.

\section{Western immunoblot analysis}

A markedly increased phosphorylation of p38 MAPK was detected in cell protein extracts of alveolar macrophages obtained from the two COPD patients compared with smoking and nonsmoking controls (fig. 4). By contrast, no differences were observed with regard to the total p38 $\alpha$ MAPK expressed by alveolar macrophages in the four subjects examined (fig. 4).

\section{DISCUSSION}

The present study shows an increase in the phosphorylated form of p38 MAPK in both alveolar macrophages and the alveolar walls of smokers with COPD. Western blot analysis confirmed the increased phospho-p38 expression in alveolar macrophages from COPD patients, in the absence of any change in total p38 $\alpha$ levels. Furthermore, phospho-p38 expression was related to the degree of lung function impairment and to the number of CD8 T-lymphocytes infiltrating the alveolar walls. To the best of the present authors' knowledge, the current study presents the first evidence obtained in human lung tissue of the potential role

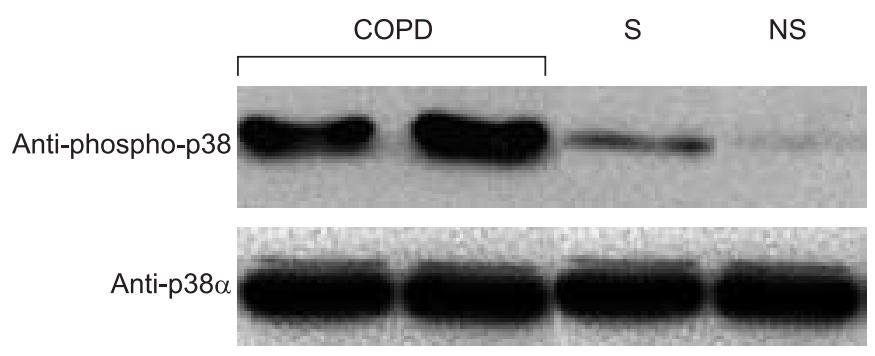

FIGURE 4. Western immunoblot analysis of activated p38 mitogen-activated protein kinase (phospho-p38) and p38 $\alpha$ isoform expressed by human alveolar macrophages obtained from two patients with chronic obstructive pulmonary disease (COPD), as well as a smoker (S) and a nonsmoker (NS), both with normal lung function. 
played by p38 activation in the inflammatory process associated with COPD.

For both immunohistochemistry and Western blot experiments, an anti-phospho-p38 monoclonal antibody was used that specifically recognises two phosphorylation sites (threonine 180 and tyrosine 182) of p38. Since dual phosphorylation involving these amino acid sites occurs in the p38 $\alpha$ and p38 $\beta$ isoforms only and expression of the $\beta$ isoform appears to be restricted to T-cells [21], it can reasonably be argued that the phospho-p38 detected in lung macrophages is predominantly the $\alpha$ isoform. Therefore, phosphorylation-dependent activation of p38 $\alpha$ is probably a leading molecular event in signalling mechanisms underlying the perpetuation of the inflammatory process in COPD. This is confirmed by the ability of p38 $\alpha$ and $-\beta$ inhibitors to suppress cytokine production in animal models of COPD [7]. In vitro, increased p38 MAPK phosphorylation has been recently shown by SMITH et al. [10] in lipopolysaccharide (LPS)-stimulated lung macrophages, whereas in the current study, high levels of phospho-p38 expression were detected in alveolar macrophages and alveolar walls in vivo.

It is well known that alveolar macrophages play a central role in the pathogenesis of COPD by continuously releasing proteolytic enzymes leading to destruction of lung tissue. These cells may also orchestrate the inflammatory response by secreting large amounts of cytokines and chemokines. p38 MAPK activation is a crucial step in the synthesis of multiple inflammatory mediators and, in particular, LPS-induced release of TNF- $\alpha$ from human lung macrophages is dependent on p38-mediated stabilisation of TNF- $\alpha$ mRNA [10]. Moreover, p38 inactivation caused by $\mathrm{p} 38 \alpha / \beta$ inhibitors significantly reduces TNF- $\alpha$ production.

The present results also refer to other cell types involved in COPD pathogenesis. In this regard, T-cells are important players in the immune response in COPD and a shift towards a type 1 profile with increased chemokine receptor CXCR3 expression and release of TNF- $\alpha$ and interferon- $\gamma$ has been described in this disease $[22,23]$. There is recent evidence that, in human bronchial epithelial cells, CXCR3-induced chemotaxis is critically dependent on signalling by the p38 MAPK pathway [24]. Moreover, in the present study, a positive correlation was seen between the numbers of phospho-p38+ cells and CD8+ cells within the alveolar walls. Together, these results suggest that there is a strict interplay between the p38 pathway and T-lymphocyte activation, which may result in perpetuation of the inflammatory response. To the best of the present authors' knowledge, it is not yet known which of the p38 isoenzymes are expressed by CD8+ T-lymphocytes. However, IL-2 production by these cells can be suppressed by a selective inhibitor of $p 38 \alpha$ and $-\beta$ [25]. These two isoforms thus appear to be the most relevant to CD8+ T-cell function [21]. Dual phosphorylation of p38 $\alpha$ and p38 $\beta$ has been detected in both CD4+ and CD8+ T-cells [26]. The availability of more specific antibodies recognising the different p38 isoforms, as well as the development of p38 inhibitors with greater selectivity, may help to better characterise the p38 subtypes preferentially expressed by CD8+ T-lymphocytes. This expression pattern may have relevant functional implications because, for example, p38 $\beta$ is a much more potent stimulator, when compared with the $\alpha$ isoform, of activating transcription factor 2 [26].

The present findings, obtained in human lung samples, confirm and extend previous studies performed in experimental models of smoking-induced pulmonary inflammation. MARWICK et al. [27] examined rat lungs exposed to cigarette smoke and detected enhanced p38 phosphorylation, associated with increased activation of the transcription factors NF- $\kappa B$ and AP-1. Furthermore, they observed significant chromatin rearrangement with hyperacetylation of histone 4 and phospho-acetylation of histone 3, together with decreased histone deacetylase (HDAC) activity. ITO et al. [28] recently investigated the expression and activity of HDAC in the peripheral lung tissue of COPD patients, showing a progressive impairment of HDAC activity paralleled by significant increases in IL-8 mRNA and histone 4 acetylation. Interestingly, the IL-8 gene is transcriptionally regulated by NF- $\mathrm{KB}$ and its activation is controlled, at least in part, by p38 MAPK-mediated histone 3 phosphorylation on serine 10 [29]. In light of all these considerations, it can be proposed that phosphorylationdependent activation of p38 MAPK may contribute, together with histone modifications, to the onset and progression of lung inflammation. This interaction may become important when considering the poor response to steroids observed not only in patients with COPD but also in smoking asthmatic patients. Several mechanisms have been proposed to explain steroid resistance; among these, it is known that activated p38 MAPK phosphorylates glucocorticoid receptors (GR) in vitro, thereby reducing corticosteroid binding affinity [30]. As a result, the transcriptional activity of genes regulated by corticosteroids will be impaired, with a consequent reduction of MAPK phosphatase (MKP)-1 expression, which is indeed induced by activated GR [31]. Therefore, it is possible that in moderate-to-severe COPD, excessive phospho-p38 activity can implement a feedforward circuit that further amplifies the role of MAPK pathways. In such a situation, p38 activation will be even more sustained because of a defective dephosphorylation due to MKP-1 downregulation.

In the present study, p38 activation in both macrophages and alveolar walls was not upregulated by tobacco-smoking itself, since a similar immunoreactivity was present in smokers with normal lung function and nonsmoking controls. Furthermore, phospho-p38 expression was not influenced by current smoking status or cumulative smoking history. This scenario is different from that observed in animal models, where exposure to tobacco smoke was sufficient to enhance p38 phosphorylation [27]. By contrast, p38 stimulation in humans is strictly related to the presence of the disease, because once fixed airflow limitation has been established, p38 MAPK activation persists even after smoking cessation. It is important to note that the inflammatory response persists in smokers with COPD long after smoking cessation [11]. Together, these observations support the view that, beyond cigarette smoking, a complex interplay of different factors (including genetic predisposition, air pollution and respiratory infections) promotes COPD, which is characterised by high variability of phenotypic expressions.

A possible limitation of the current study is that it was performed on surgical specimens mainly taken from patients 
with lung carcinoma, and the presence of the cancer itself may possibly have influenced MAPK activation. The present authors tried to avoid this bias by taking into consideration only histologically normal areas, characterised as being free of tumour and distant from affected areas. Moreover, since lung cancer was equally present in mild/moderate COPD, in smoking and nonsmoking controls, it is likely that the finding of an increased phosphorylation of p38 in COPD is valid. Finally, the present results were further validated as p38 activation was also observed in patients not affected by cancer (i.e. those with severe emphysema undergoing LVRS). It should be acknowledged that, ideally, a true control group of nonsmokers without concomitant lung cancer is required in studies such as the present one; however, it is extremely difficult to secure surgical specimens from healthy people in whom a complete clinical and functional characterisation has been performed.

In conclusion, the current study demonstrated an increased expression of activated p38 mitogen-activated protein kinase in alveolar spaces and alveolar walls of smokers with chronic obstructive pulmonary disease, suggesting that activation of the p38 mitogen-activated protein kinase pathway is a crucial step in the pathogenesis of the disease. These findings support the relevance of p38 mitogen-activated protein kinase as a suitable molecular target for the development of new and more effective therapeutic strategies for chronic obstructive pulmonary disease.

\section{ACKNOWLEDGEMENTS}

The authors thank C.A. Drace (Dept of Cardiac, Thoracic and Vascular Sciences, University of Padova, Padova, Italy) for assistance in editing the present manuscript.

\section{REFERENCES}

1 Rahman I, Adcock IM. Oxidative stress and redox regulation of lung inflammation in COPD. Eur Respir J 2006; 28: 219-242.

2 MacNee W, Rahman I. Is oxidative stress central to the pathogenesis of chronic obstructive pulmonary disease? Trends Mol Med 2000; 7: 43-62.

3 Bowler RP, Barnes PJ, Crapo JD. The role of oxidative stress in chronic obstructive pulmonary disease. COPD 2004; 2: 255-277.

4 Nebreda AR, Porras A. p38 MAP kinases: beyond the stress response. Trends Biochem Sci 2000; 25: 257-260.

5 Pelaia G, Cuda G, Vatrella A, et al. Mitogen-activated protein kinases and asthma. J Cell Physiol 2005; 202: 642-653.

6 Shaffer HJ, Weber MJ. Mitogen-activated protein kinases: specific messages from ubiquitous messengers. Mol Cell Biol 1999; 19: 2435-2444.

7 Adcock IM, Chung KF, Caramori G, Ito K. Kinase inhibitors and airway inflammation. Eur J Pharmacol 2006; 533: 118-132.

8 Stellato C. Post-transcriptional and nongenomic effects of glucocorticoids. Proc Am Thorac Soc 2004; 1: 255-263.

9 Barnes PJ. Novel signal transduction modulators for the treatment of airway diseases. Pharmacol Ther 2006; 109: 238-245.

10 Smith SJ, Fenwick PS, Nicholson AG, et al. Inhibitory effect of p38 mitogen-activated protein kinase inhibitors on cytokine release from human macrophages. $\mathrm{Br} J$ Pharmacol 2006; 149: 393-404.

11 Turato G, Di Stefano A, Maestrelli P, et al. Effect of smoking cessation on airway inflammation in chronic bronchitis. Am J Respir Crit Care Med 1995; 152: 1262-1267.

12 Renda T, Baraldo S, Pelaia G, et al. Expression of phosphorylated p38 MAPK in the lung of smokers with COPD. Eur Respir J 2006; 28: Suppl. 50, 582s.

13 Celli BR, MacNee W, Agusti A, et al. Standards for the diagnosis and treatment of patients with COPD: a summary of the ATS/ERS position paper. Eur Respir J 2004; 23: 932-946.

14 Miniati M, Filippi E, Falaschi F, et al. Radiologic evaluation of emphysema in patients with chronic obstructive pulmonary disease: chest radiography versus high resolution computed tomography. Am J Respir Crit Care Med 1995; 151: 1359-1367.

15 Saetta M, Di Stefano A, Maestrelli P, et al. Airway eosinophilia in chronic bronchitis during exacerbations. Am J Respir Crit Care Med 1994; 150: 1646-1652.

16 The World Medical Association (WMA). World Medical Association Declaration of Helsinki Ethical Principles for Medical Research Involving Human Subjects, 2000. www.wma.net/e/policy/b3.htm. Date last updated: September 10, 2004.

17 Saetta M, Baraldo S, Corbino L, et al. CD8+ve cells in the lungs of smokers with chronic obstructive pulmonary disease. Am J Respir Crit Care Med 1999; 160: 711-717.

18 Maestrelli P, El Messlemani AH, De Fina O, et al. Increased expression of heme oxygenase $(\mathrm{HO})-1$ in alveolar spaces and HO-2 in alveolar walls of smokers. Am J Respir Crit Care Med 2001; 164: 1508-1513.

19 Baraldo S, Turato G, Badin C, et al. Neutrophilic infiltration within the airway smooth muscle in patients with COPD. Thorax 2004; 59: 308-312.

20 Chakrabarty K, Wu W, Booth JL, Duggan ES, Coggeshall KM, Metcalf JP. Bacillus anthracis spores stimulate cytokine and chemokine innate immune responses in human alveolar macrophages through multiple mitogen-activated protein kinase pathways. Infect Immun 2006; 74: 4430-4438.

21 Hale KK, Trollinger D, Rihanek M, Manthey CL. Differential expression and activation of p38 mitogenactivated protein kinase $\alpha, \beta, \gamma$, and $\delta$ in inflammatory cell lineages. J Immunol 1999; 162: 4246-4252.

22 Grumelli S, Corry DB, Song LZ, et al. An immune basis for lung parenchymal destruction in chronic obstructive pulmonary disease and emphysema. PLoS Med 2004; 1: e8.

23 Saetta M, Mariani M, Panina-Bordignon P, et al. Increased expression of the chemokine receptor CXCR3 and its ligand CXCL10 in peripheral airways of smokers with chronic obstructive pulmonary disease. Am J Respir Crit Care Med 2002; 165: 1404-1409.

24 Shahabuddin S, Ji R, Wang P, et al. CXCR3 chemokine receptor-induced chemotaxis in human airway epithelial cells: role of p38 MAPK and PI3K signalling pathways. Am J Physiol Cell Physiol 2006; 291: C34-C39.

25 Tham EL, Mescher MF. Signaling alterations in activationinduced nonresponsive CD8 T cells. J Immunol 2001; 167: 2040-2048. 
26 Ashwell JD. The many paths to p38 mitogen-activated protein kinase activation in the immune system. Nat Rev Immunol 2006; 6: 532-540.

27 Marwick JA, Kirkham PA, Stevenson CS, et al. Cigarette smoke alters chromatin remodelling and induces proinflammatory genes in rat lung. Am J Respir Cell Mol Biol 2004; 31: 633-642.

28 Ito $\mathrm{K}$, Ito $\mathrm{M}$, Elliott $\mathrm{WM}$, et al. Decreased histone deacetylase in chronic obstructive pulmonary disease. $N$ Engl J Med 2005; 352: 1967-1976.
29 Saccani S, Pantano S, Natoli G. p38-dependent marking of inflammatory genes for increased NF- $\mathrm{B}$ recruitment. Nat Immunol 2002; 3: 69-75.

30 Irusen E, Matthews JG, Takahashi A, Barnes PJ, Chung KF, Adcock IM. p38 mitogen-activated protein kinase-induced glucocorticoid receptor phosphorylation reduces its activity: role in steroid-insensitive asthma. J Allergy Clin Immunol 2002; 109: 649-657.

31 Barnes PJ. Corticosteroid effects on cell signalling. Eur Respir J 2006; 27: 413-426. 